\title{
3D printing of high-strength bioscaffolds for the synergistic treatment of bone cancer
}

\author{
Hongshi Ma ${ }^{1,2}$, Tao $\mathrm{Li}^{3}$, Zhiguang Huan ${ }^{1}$, Meng Zhang ${ }^{1}$, Zezheng Yang ${ }^{3}$, Jinwu Wang ${ }^{3}$, Jiang Chang ${ }^{1}$ and \\ Chengtie $\mathrm{Wu}^{1}$
}

\begin{abstract}
The challenges in bone tumor therapy are how to repair the large bone defects induced by surgery and kill all possible residual tumor cells. Compared to cancellous bone defect regeneration, cortical bone defect regeneration has a higher demand for bone substitute materials. To the best of our knowledge, there are currently few bifunctional biomaterials with an ultra-high strength for both tumor therapy and cortical bone regeneration. Here, we designed $\mathrm{Fe}_{-} \mathrm{CaSiO}_{3}$ composite scaffolds (30CS) via 3D printing technique. First, the 30CS composite scaffolds possessed a high compressive strength that provided sufficient mechanical support in bone cortical defects; second, synergistic photothermal and ROS therapies achieved an enhanced tumor therapeutic effect in vitro and in vivo. Finally, the presence of $\mathrm{CaSiO}_{3}$ in the composite scaffolds improved the degradation performance, stimulated the proliferation and differentiation of rBMSCs, and further promoted bone formation in vivo. Such 30CS scaffolds with a high compressive strength can function as versatile and efficient biomaterials for the future regeneration of cortical bone defects and the treatment of bone cancer.
\end{abstract}

\section{Introduction}

The treatment of bone cancer has received considerable attention from scientists and clinicians ${ }^{1,2}$. The challenges in the therapeutic process are how to repair the large bone defects induced by surgery and kill all possible residual tumor cells ${ }^{3}$. Compared to cancellous bone defect regeneration, cortical bone defect regeneration has a higher demand for bone substitute materials, which should not only have satisfactory biological activities but also possess a high compressive strength to match that of cortical bone. To the best of our knowledge, there are

\footnotetext{
Correspondence: Jinwu Wang (wangjw@sjtu.edu.cn) or Chengtie Wu (chengtiewu@mail.sic.ac.cn)

${ }^{1}$ State Key Laboratory of High Performance Ceramics and Superfine Microstructure, Shanghai Institute of Ceramics, Chinese Academy of Sciences, 200050 Shanghai, People's Republic of China

'University of Chinese Academy of Sciences, 100043 Beijing, People's Republic of China

Full list of author information is available at the end of the article.

These authors contributed equally: Hongshi Ma, Tao Li
}

currently few bifunctional biomaterials with an ultra-high strength for both tumor therapy and cortical bone regeneration. Therefore, it is of great significance to develop such biomaterials for potential application in the treatment of bone tumors.

Compared with inorganic bioceramics and polymeric scaffolds, metal scaffolds, such as Fe scaffolds, have an excellent fatigue resistance and a high compressive strength, which are suitable for repairing load-bearing bone defects ${ }^{4}$. Although Fe-based materials have been demonstrated to possess good biocompatibility and biosafety $^{5-8}$, pure Fe materials still have a number of deficiencies in practical applications, such as a rather low degree of degradation, lack of bioactivity and poor boneforming performance ${ }^{9,10}$. In contrast, inorganic $\mathrm{CaSiO}_{3}$ bioceramics have fast ion release kinetics due to their low value of activation ${ }^{11}$. In addition, $\mathrm{CaSiO}_{3}$ bioceramics can stimulate vascularization and osteogenic differentiation and further promote bone formation in vivo ${ }^{12}$. Therefore,

\section{(c) The Author(s) 2018}

(c) (i) Open Access This article is licensed under a Creative Commons Attribution 4.0 International License, which permits use, sharing, adaptation, distribution and reproduction cc) in any medium or format, as long as you give appropriate credit to the original author(s) and the source, provide a link to the Creative Commons license, and indicate if changes were made. The images or other third party material in this article are included in the article's Creative Commons license, unless indicated otherwise in a credit line to the material. If material is not included in the article's Creative Commons license and your intended use is not permitted by statutory regulation or exceeds the permitted use, you will need to obtain permission directly from the copyright holder. To view a copy of this license, visit http://creativecommons.org/licenses/by/4.0/. 

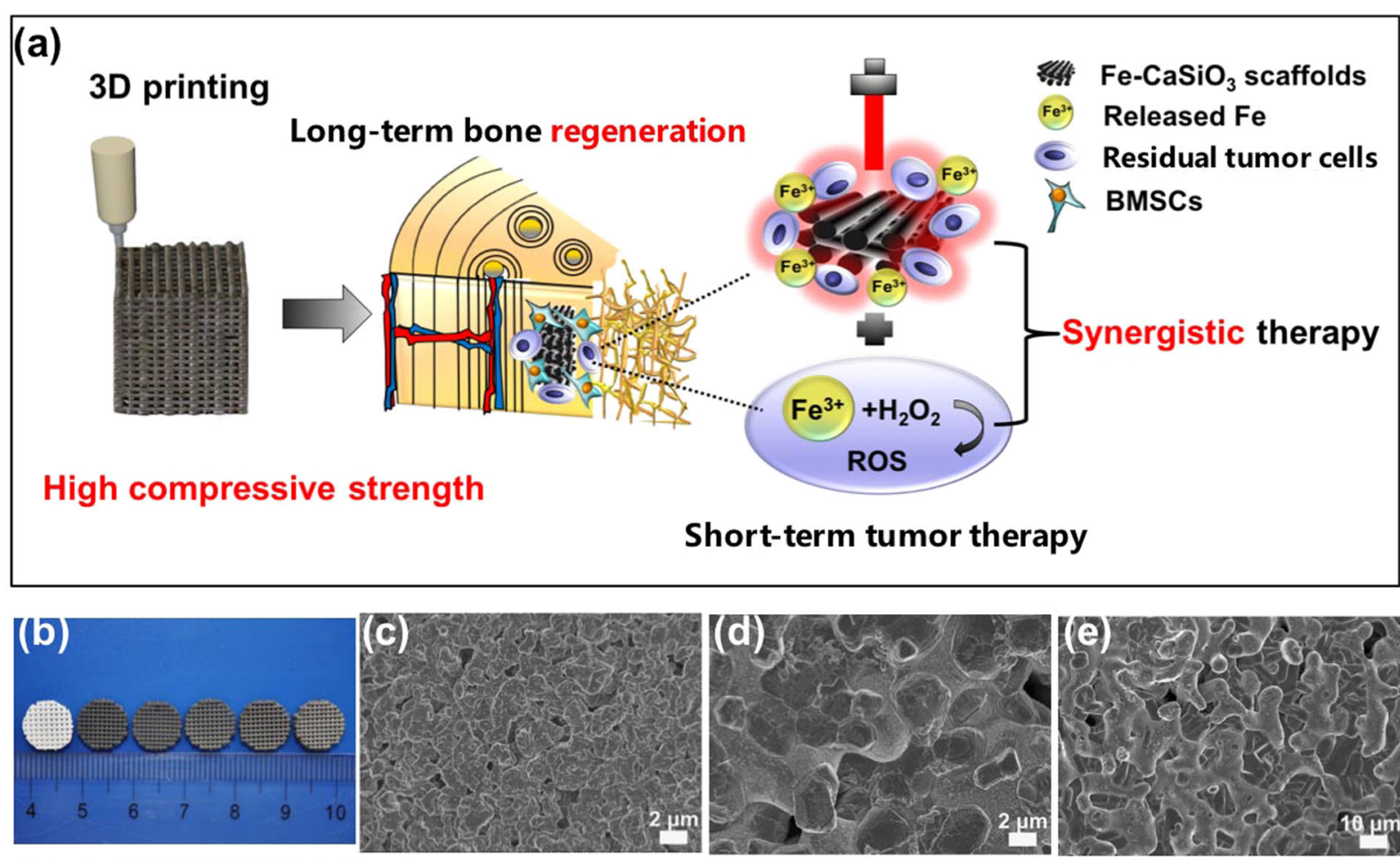
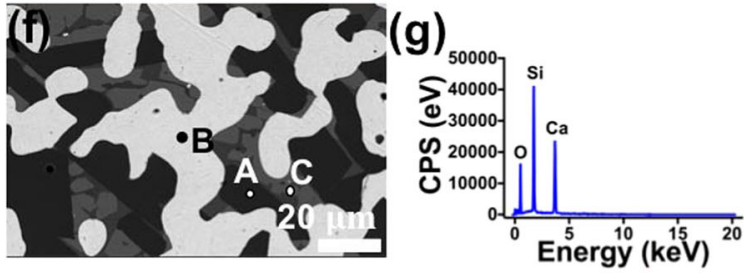

(h)
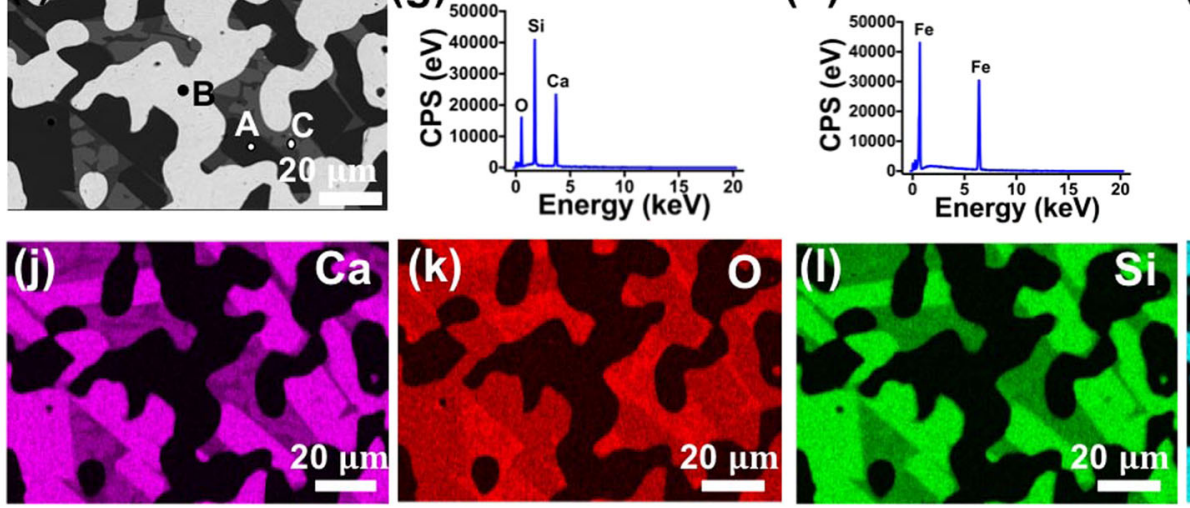

(i)
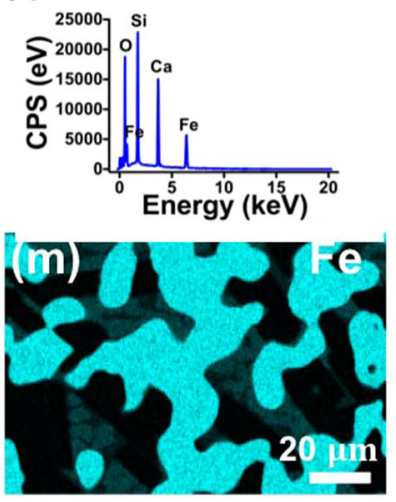

Fig. 1 a Schematic illustration of the fabrication of $\mathrm{Fe}_{-} \mathrm{CaSiO}_{3}$ composite scaffolds and their bioapplication. $\mathbf{b}$ Photograph of the 3D-printed scaffolds $\left(\mathrm{CaSiO}_{3}, 40 \mathrm{CS}, 30 \mathrm{CS}, 20 \mathrm{CS}, 10 \mathrm{CS}\right.$, and Fe, respectively). Scanning electron microscopy (SEM) images of the $\mathrm{CaSiO}_{3}$ (c), Fe (d), 30CS (e) scaffolds sintered at $1350^{\circ} \mathrm{C}$. $\mathbf{f}$ Back-scattered electron image of a 30CS scaffold after a polishing process. Energy dispersive spectroscopy (EDS) results for the $30 \mathrm{CS}$ scaffold at spots A, B, and C, corresponding to spectrum ( $\mathbf{g}$ ), spectrum (h) and spectrum (i). Energy-dispersive spectroscopy (EDS) elemental mapping of the 30CS scaffold after the polishing process: $\mathrm{Ca}(\mathbf{j}), \mathrm{O}(\mathbf{k}), \mathrm{Si}(\mathbf{I}), \mathrm{Fe}(\mathbf{m})$. There is a clear diffusion of Fe into $\mathrm{CaSiO}_{3}$ ceramic phase

inorganic-metal composite scaffolds with desirable architectures and mechanical properties and satisfactory biocompatibility, bioresorbability and osteogenesis are promising for solving the issues associated with traditional scaffolds and ultimately for meeting the clinical requirements.

Photothermal therapy has been extensively explored owing to its minimally invasive procedure and specific temporal and spatial selectivity ${ }^{13-15}$. It has been reported that Fe nanoparticles possess photothermal effects owing to their localized surface plasmon resonance, and they are easy to ignite due to their higher temperature increase, lower activation energy, and porous oxide structure ${ }^{16}$. Despite the above encouraging results, to the best of our knowledge, there are no reports on the photothermal therapeutic effect of Fe-based biomaterials in vitro and in vivo. Interestingly, apart from the photothermal effect, the release of Fe ions capable of catalytic $\mathrm{H}_{2} \mathrm{O}_{2}$ decomposition inside the tumor leads to the production of reactive oxygen species (ROS), resulting in rapid lipid 
oxidation and protein and DNA damage, which are harmful to tumor cells ${ }^{17}$. Such synergistic photothermal and reactive oxygen species therapies can improve the tumor therapeutic effect compared with the monomodal therapies $^{18,19}$.

In this work, we designed a $\mathrm{Fe}-\mathrm{CaSiO}_{3}$ composite scaffold named 30CS via a facile ball-milling and 3D printing technique (mass percent: $30 \% \mathrm{CaSiO}_{3}$ and $70 \%$ $\mathrm{Fe}$ ). The composite scaffolds with a high compressive strength exhibited the synergistic effects of photothermal and ROS tumor therapies and the ability to promote bone regeneration. Such a unique scaffold featured the following advantages: First, the 30CS composite scaffolds possessed a high compressive strength that provided sufficient mechanical support in bone cortical defects; second, the 30CS scaffolds could serve as photothermal agents owing to their excellent photothermal effect. Simultaneously, the sustained release of $\mathrm{Fe}$ ions from the 30CS scaffolds induced a constant tumor therapeutic effect. Such synergistic photothermal and ROS therapies achieved an enhanced therapeutic effect and effectively inhibited tumor growth in vivo. Finally, the 30CS scaffolds supported the adhesion, proliferation, and osteogenic differentiation of rBMSCs and promoted bone formation in vivo. Therefore, such 30CS scaffolds with a high compressive strength are promising for future applications in the therapy of cortical bone cancer and the regeneration of cortical bone defects resulting from surgery. A schematic illustration of the fabrication and bioapplication of the $\mathrm{Fe}-\mathrm{CaSiO}_{3}$ composite scaffolds is shown in Fig. 1a.

\section{Method}

Materials

Iron powder with a $99.5 \%$ purity was purchased from Haotian Nano Technology, China. $\mathrm{CaSiO}_{3}$ powder was purchased from Kunshan Chinese Technology New Materials Co. Pluronic F-127, tri-methylolaminomethane, calcein AM, ethidium homodimer-1, fluorescein isothiocyanate (FITC) and 4',6-diamidino-2-phenylindole (DAPI) were purchased from Sigma-Aldrich (USA). CCK8 and DCFH-DA were purchased from Beyotime Biotechnology (China).

\section{Preparation and characterization of the 30CS scaffolds}

The composite powder was first prepared by mixing $\mathrm{Fe}$ and $\mathrm{CaSiO}_{3}$ powders $\left(\mathrm{CaSiO}_{3}\right.$ mass percent: $40,30,20$, $10 \%$ ) and then ball milling for $2 \mathrm{~h}$. The products are denoted 40CS, 30CS, 20CS, 10CS, respectively. Composite scaffolds were fabricated by $3 \mathrm{D}$ printing based on a computer-aided design model, dried at room temperature for $24 \mathrm{~h}$, and then sintered at 1150,1250 , and $1350{ }^{\circ} \mathrm{C}$ in an argon atmosphere.
The surface microstructure and elemental mapping of $\mathrm{CaSiO}_{3}$, Fe and the composite scaffolds were characterized by scanning electron microscopy with an energydispersive spectrometer (SU8220, HITACHI, Tokyo, Japan). The effect of the sintering temperature on the crystalline structure of the ceramic scaffolds was investigated via X-ray diffraction analysis (D8 ADVANCE, BRUKER AXS GMBH, Karlsruhe, Germany).

To investigate the ion release from the scaffolds and their weight loss, the scaffolds were soaked in a Tris- $\mathrm{HCl}$ solution for $1,7,14,21$, and 28 days (solution volume to scaffold mass: $200 \mathrm{~mL} / \mathrm{g}$ ), dried at $120^{\circ} \mathrm{C}$, and weighed via an analytical balance. Every 7 days, the Tris- $\mathrm{HCl}$ solution was collected and refreshed. The concentrations of $\mathrm{Ca}, \mathrm{Si}$ and $\mathrm{Fe}$ ions were measured by inductively coupled plasma atomic emission spectrometry (ICP-AES, Vista AX, Varian, Palo Alto, USA). To investigate the effect of the sintering temperature on the degradation and release of $\mathrm{Fe}$ ions, 30CS and Fe scaffolds sintered at 1150 and $1350^{\circ} \mathrm{C}$ were soaked in a Tris- $\mathrm{HCl}$ solution for 1,3 , and 7 days, and then the Fe ion concentration was detected via ICPAES.

To determine the compressive strength of the scaffolds, cube specimens with a height of $10 \mathrm{~mm}$ were prepared. The compression tests were carried out via a universal testing machine (Instron-5592, Norwood, USA) at room temperature.

The photothermal effects of the 30CS scaffolds were evaluated with an $808 \mathrm{~nm}$ NIR laser at power densities of $0.4,0.45,0.5,0.55$, and $0.6 \mathrm{~W} / \mathrm{cm}^{2}$ in the dry state and in PBS. The temperature of the scaffold was monitored by an infrared thermal imaging system in real time. The temperature of the scaffold was exported to plot the curves via FLIR R\&D software.

\section{Detection of the reactive oxygen species produced by the $30 \mathrm{CS}$ scaffolds in vitro}

Sao2 tumor cells were incubated in MEM medium containing $10 \%$ fetal bovine serum at $37^{\circ} \mathrm{C}$ in a humidified incubator $\left(5 \% \mathrm{CO}_{2}\right)$. A total of $1.5 \times 10^{5}$ cells were cultured in 6-well plates for $48 \mathrm{~h}$, and then scaffolds were gently placed on the plates. After $4 \mathrm{~h}$, the scaffolds were removed, and the Sao2 cells were washed with MEM medium twice and then loaded with DCFH-DA for $20 \mathrm{~min}$ ( $1.5 \mathrm{~mL}$ for each well). Then, the probe was removed, and the tumor cells were washed with MEM twice, collected by trypsin and re-dispersed in the MEM medium. The intracellular ROS level was detected via the fluorescence intensity of DCF in the Sao2 cells using a fluorescence spectrometer. In addition, after treatment with DCFH-DA for $20 \mathrm{~min}$, the fluorescence could be directly observed via fluorescence microscopy at $480 \mathrm{~nm}$ excitation. 


\section{In vitro antitumor efficiency of the 30CS scaffolds}

The cells were cultured in 48-well plates at a density of $1 \times 10^{4}$ per well and then incubated for $48 \mathrm{~h}$. Then, the cells were divided into nine groups: those treated with $\mathrm{CaSiO}_{3}, \mathrm{Fe}$ or $30 \mathrm{CS}$ without irradiation for $4 \mathrm{~h}$; those treated with $\mathrm{CaSiO}_{3}, \mathrm{Fe}$ or $30 \mathrm{CS}$ for $4 \mathrm{~h}$ and then irradiated at a power density of $0.6 \mathrm{~W} / \mathrm{cm}^{2}$ for $15 \mathrm{~min}$; and those in which $\mathrm{CaSiO}_{3}, \mathrm{Fe}$ or $30 \mathrm{CS}$ was placed gently on the plate, irradiated for $15 \mathrm{~min}$ and then removed immediately. For another $12 \mathrm{~h}$, the medium was replaced with a CCK-8 solution and kept at $37^{\circ} \mathrm{C}$ for $1 \mathrm{~h}$. Then, the absorbance at $405 \mathrm{~nm}$ was recorded via a microplate reader (Biotek Instruments, Winooski, USA).

To visually observe the viability of the tumor cells among the nine groups, after the different treatments, the tumor cells were stained with calcein AM (green fluorescence, live cells) and ethidium homodimer-1 (red fluorescence, dead cells) for $30 \mathrm{~min}$ to distinguish the live cells from the dead cells. The fluorescence emitted from the cells was observed via a confocal laser scanning microscope (Leica TCS SP8, Wetzlar, Germany).

The biocompatibility of rBMSCs after treatment with $\mathrm{CaSiO}_{3}$, Fe or $30 \mathrm{CS}$ for $4 \mathrm{~h}$ was also tested via CCK-8 (cell counting kit-8) assay. The rBMSCs were cultured in 48well plates at a density of $1 \times 10^{4}$ per well and then incubated for $48 \mathrm{~h}$. Then, $\mathrm{CaSiO}_{3}$, Fe or $30 \mathrm{CS}$ scaffolds were gently placed in the well. After $4 \mathrm{~h}$, the scaffolds were removed, and after another $12 \mathrm{~h}$, the rBMSCs were cultured with CCK-8 solution for $1 \mathrm{~h}$. Then, the absorbance at $405 \mathrm{~nm}$ was recorded via a microplate reader (Biotek instruments, Winooski, USA).

The effect of the power density on the viability of the rBMSCs was also investigated. First, rBMSCs were cultured in 48-well plates at a density of $1 \times 10^{4}$ per well and then incubated for $48 \mathrm{~h} . \mathrm{CaSiO}_{3}$, Fe or 30CS scaffolds were gently placed on the plates, and the cells were divided into the following groups: those without irradiation and those with irradiation at power densities of 0.16 , 0.27 , or $0.44 \mathrm{~W} / \mathrm{cm}^{2}$ for $15 \mathrm{~min}$. After irradiation for 15 min, the scaffolds were removed immediately. After another $12 \mathrm{~h}$, the cell viability was determined by CCK- 8 assay. The rBMSCs irradiated at a power density of 0.16 $\mathrm{W} / \mathrm{cm}^{2}$ for $15 \mathrm{~min}$ were incubated for another 1 and 3 days. Then, the proliferation of the rBMSCs was analyzed by the CCK- 8 assay.

\section{In vivo antitumor efficiency of the 30CS scaffolds}

Tumor-bearing mice (4-6 weeks old) were obtained from the Laboratory Animal Center, Shanghai Ninth People's Hospital Affiliated Shanghai, Jiao Tong University School of Medicine, and the mice model was performed according to the previous study. Briefly, Saos-2 tumor cells $\left(5 \times 10^{6}\right.$ cells $)$ were injected into the back of the nude mice in each group. When the tumor volume reached $\sim 200 \mathrm{~mm}^{3}$, the mice were divided into six groups randomly $(n=5)$, implanted with $\mathrm{CaSiO}_{3}, \mathrm{Fe}$ or 30CS scaffolds and either not irradiated or irradiated with a laser. The scaffold (length: $6 \mathrm{~mm}$, width: $1.5 \mathrm{~mm}$, height: $1.5 \mathrm{~mm}$ ) was implanted in the center of the tumor tissue. For the PTT treatment, the mice were irradiated with a $808 \mathrm{~nm}$ laser for $10 \mathrm{~min}$ at a power density of $\sim 0.8 \mathrm{~W} / \mathrm{cm}^{2}$ and monitored via IR thermal imaging system in real time. Every other day, the tumor volume was recorded with a caliper. On the 15th day, the mice were sacrificed and photographed. Then, the tumor tissue was collected, weighed, immersed in a $4 \%$ formaldehyde solution for $24 \mathrm{~h}$, embedded in paraffin, and stained with H\&E.

\section{In vitro osteogenesis of the $30 \mathrm{CS}$ scaffolds}

rBMSCs were cultured to the third passage, and then $5 \times 10^{3} \mathrm{rBMSC}$ were cultured in 96-wells plates for 1,3 , and 5 days in the extracts of $\mathrm{CaSiO}_{3}, \mathrm{Fe}$ and 30CS powders or scaffolds. The proliferation of rBMSCs was analyzed by the CCK- 8 assay. Briefly, the extracts were removed, and then the rBMSCs were incubated with a $10 \%$ CCK-8 solution $(250 \mu \mathrm{l}$ in each well) for $1 \mathrm{~h}$. Then, $100 \mu \mathrm{L}$ of the CCK- 8 solution was extracted from each well, and the absorption was measured at $405 \mathrm{~nm}$ via a multifunction microplate reader.

To investigate the mRNA transcription levels of bonerelated genes (COLI, RUNX2, OPN and BMP2), the rBMSCs were processed for total RNA extraction via an RNAprep Micro Kit (TaKaRa, Japan) at 1 and 3 day. The concentration of RNA was detected at $260 \mathrm{~nm}$ using a multifunctional microplate reader (SpectraFluor Plus, Tecan, Crailsheim, Germany). cDNA was prepared by the PrimeScript 1st Strand cDNA synthesis kit (TOYOBO, Japan). Then, RT-qPCR was performed via SYBR Green QPCR Master Mix (TaKaRa, Japan) with a Light Cycler apparatus (Bio-rad, CFX-Touch).

To evaluate the cell morphology in the $\mathrm{CaSiO}_{3}, \mathrm{Fe}$ and 30CS scaffolds, $1 \times 10^{4} \mathrm{rBMSCs}$ were cultured in each scaffold in a 48-well plate. After 1 day, the scaffolds were washed with phosphate-buffered saline and then fixed with $2.5 \%$ glutaraldehyde, a series of ethanol solutions (30, $50,70,80,90,95$, and $100 \mathrm{v} / \mathrm{v} \%$ ) and hexamethyldisilazane. Finally, the cellular scaffolds were observed by SEM (SU8220, HITACHI, Tokyo, Japan).

To observe the attachment of rBMSCs to the scaffolds, rBMSCs were cultured in the scaffolds for $1 \mathrm{~d}$, incubated with $4 \%$ paraformaldehyde for $20 \mathrm{~min}$, and washed with PBS three times. The cytoskeleton and nuclei of the rBMSCs in the scaffolds were stained with FITC and DAPI, respectively. Confocal images were obtained using a confocal laser scanning microscope (Leica TCS SP8, Wetzlar, Germany). 
(a)

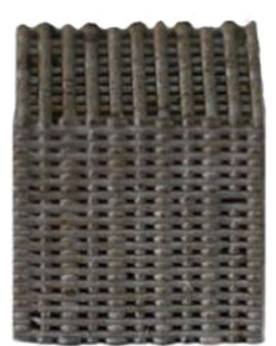

(d)

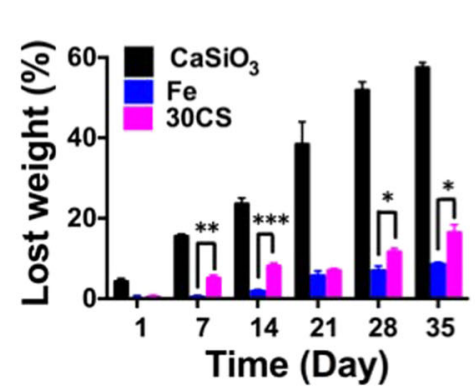

(g)

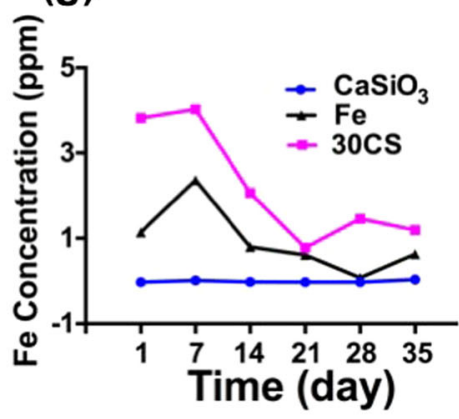

(j)

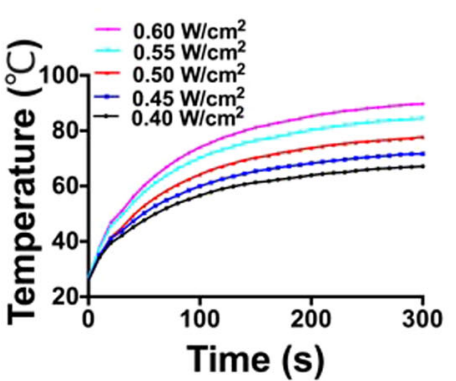

(b)

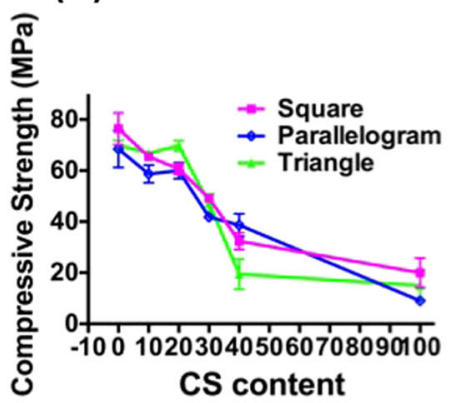

(e)

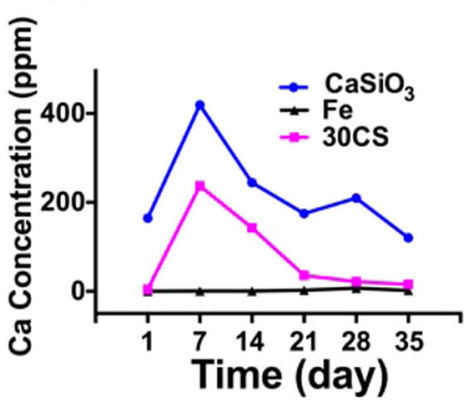

(h)

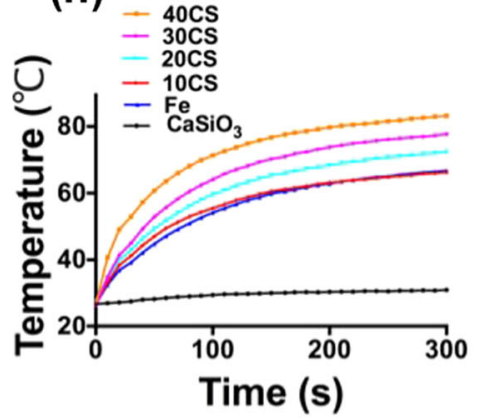

(k)

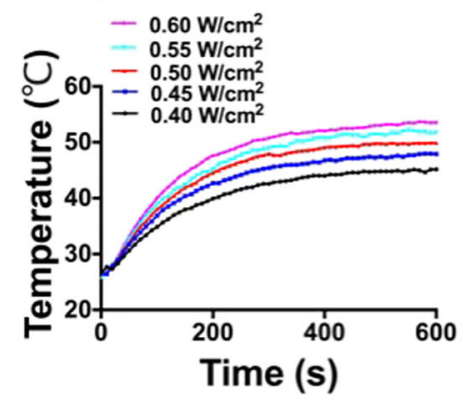

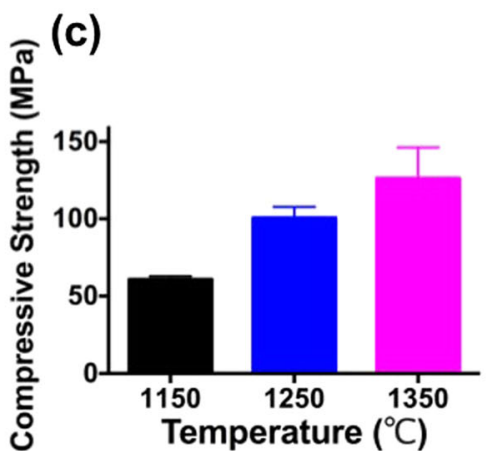

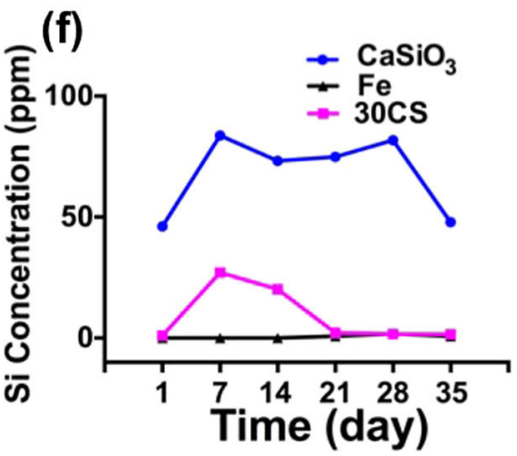

(i)

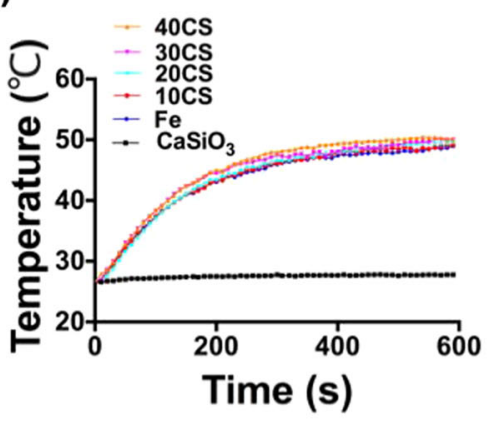

(I)

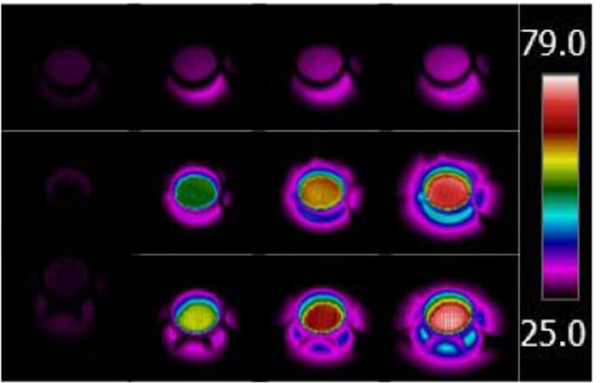

Fig. 2 Photograph of a 3D-printed Fe-CaSiO 3 composite scaffold for the compressive strength test (a). $\mathbf{b}$ Compressive strength of Fe scaffolds with different contents of CS and macroporous structures. c Compressive strength of 30CS scaffolds prepared at different sintering temperatures. d Degradation behavior of the $\mathrm{CaSiO}_{3}$, Fe and 30CS scaffolds in a Tri-HCl solution ( $\left.\mathrm{pH}=7.4\right)$. Release profiles of $\mathrm{Ca}(\mathbf{e})$, Si (f), and Fe (g) from the scaffolds in a Tri-HCl solution. Heating curves of the Fe-based scaffolds with different contents of CS in the dry state (h) and in PBS (i). Heating curves

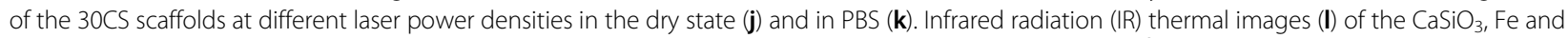
30CS scaffolds (from top to bottom) in the dry state under NIR irradiation at a power density of $0.6 \mathrm{~W} / \mathrm{cm}^{2}$ for 5 min. The $30 C S$ scaffolds had the advantage of a high compressive strength, showing potential for regenerating load-bearing bone defects and exhibiting excellent photothermal performance. $\left({ }^{*} p<0.05,{ }^{* *} p<0.01,{ }^{* *} p<0.001\right)$ 


\section{In vivo osteogenesis of $30 \mathrm{CS}$ scaffolds}

All procedures were performed according to the guidelines of the Animal Research Committee of the Ninth People's Hospital, Shanghai Jiao Tong University. Eighteen New Zealand rabbits $(2-2.5 \mathrm{~kg})$ were used as critical-sized femoral defect models to evaluate the osteogenic capabilities of the $\mathrm{CaSiO}_{3}$, Fe and 30CS scaffolds $(n=6)$. After defects were created, $\mathrm{CaSiO}_{3}, \mathrm{Fe}$ and 30CS scaffolds (height: $8 \mathrm{~mm}$, diameter: $5 \mathrm{~mm}$ ) were implanted and then irradiated at a power density of $\sim 0.8$ $\mathrm{W} / \mathrm{cm}^{2}$ for $10 \mathrm{~min}$ to verify that the short-time photothermal therapy had no adverse effects on long-term bone regeneration. After 8 weeks, the rabbits were sacrificed, and the species (the femoral tissue implanted with scaffolds) were collected and then examined via micro-CT and histological analysis via Van Gieson's picrofuchsin stain. With a software analysis system, the percentage of new bone in the total bone defect area was quantified.

\section{Results and discussion}

Synthesis and characterization of the 30CS scaffolds

In our study, the $\mathrm{Fe}-\mathrm{CaSiO}_{3}$ composite powder was obtained by ball-milling, and then 40CS, 30CS, 20CS, $10 \mathrm{CS}\left(\mathrm{CaSiO}_{3}\right.$ mass percent: 40, 30, 20, and $10 \%$, respectively) and pure Fe scaffolds were fabricated by a 3D printing method. Photographs of the 3D-printed scaffolds $\left(\mathrm{CaSiO}_{3}, 40 \mathrm{CS}, 30 \mathrm{CS}, 20 \mathrm{CS}, 10 \mathrm{CS}\right.$, and $\mathrm{Fe}$, respectively) are shown in Fig. 1b. The composite scaffolds were sintered at 1150,1250 , and $1350^{\circ} \mathrm{C}$ under an argon atmosphere, and scanning electron microscopy (SEM) images were obtained (Fig. 1c-e, Fig. S1). As shown in Fig. 1e, the two main components of 30CS were well integrated. According to the back-scattered electron image (Fig. 1f) and energy dispersive spectroscopy (EDS) analysis (Fig. 1g-i), the detailed observations revealed that there were three phases: $\mathrm{CaSiO}_{3}$ ceramics (black background), metal (Fe) phase (bright background), and $\mathrm{Fe}-\mathrm{CaSiO}_{3}$ phase (gray background). EDS elemental mapping also clearly showed the diffusion of $\mathrm{Fe}$ into the $\mathrm{CaSiO}_{3}$ ceramic phase (Fig. 1j-m). The diffusion process is dependent on the mean particle diameter of the powders, the thermal removal of the placeholder, and the pore $\operatorname{size}^{20}$. The XRD results showed that a little $\mathrm{Fe}_{3} \mathrm{O}_{4}$ was present in the 30CS scaffolds sintered at $1350^{\circ} \mathrm{C}$ (JCPDS card no. 19-0629) (Fig. S3).

\section{High mechanical strength of the 30CS scaffolds}

One of the distinctive characteristics of the prepared Fe$\mathrm{CaSiO}_{3}$ composite scaffolds is that they possess a high mechanical strength for load-bearing applications. The compressive strengths of the scaffolds were obtained from the compression curves at a strain of $30 \%$. As shown in Fig. $2 \mathrm{~b}$, the compressive strengths of the $\mathrm{Fe}-\mathrm{CaSiO}_{3}$ composite scaffolds were obviously higher than that of the
$\mathrm{CaSiO}_{3}$ scaffold without Fe. In addition, with increasing content of Fe particles, the compressive strengths of the composite scaffolds increased because of the inherent mechanical properties of Fe (Fig. 2b $)^{21}$. In terms of the different macropore morphologies (square, parallelogram, triangle), there was no significant difference in the scaffolds with the same composition. In addition, the porosities of the 30CS scaffolds with different macropore morphologies were not obviously different (Fig. S2). Furthermore, the mechanical properties of the 30CS scaffolds were significantly improved by adjusting the sintering temperature $\left(1150-1350^{\circ} \mathrm{C}\right)$, which was attributed to the fact that the enhanced compressibility and integration of the particles during the sintering process at a higher temperature leads to a lower porosity and higher densification of the 30CS scaffolds ${ }^{22}$. Fig. $2 \mathrm{c}$ shows that the 3D-printed 30CS scaffolds exhibited a very high compressive strength of $126 \mathrm{MPa}$ at a sintering temperature of $1350^{\circ} \mathrm{C}$, while the compressive strength of the $\mathrm{CaSiO}_{3}$ scaffolds reached only $14.9 \mathrm{MPa}$. As is known, the compressive strength of human compact bone ranges from 90 to $170 \mathrm{MPa}^{23}$, suggesting that the $30 \mathrm{CS}$ scaffolds can provide sufficient mechanical support for loadbearing applications after implantation into cortical bone defect sites.

\section{Degradation performance of the 30CS scaffolds}

To investigate ion release from the scaffolds and their weight loss, the scaffolds were soaked in a Tris- $\mathrm{HCl}$ solution for $1,7,14,21$, and 28 days. The $\mathrm{CaSiO}_{3}$ ceramic scaffolds exhibited the largest weight loss due to their highest degradation rate in the $\mathrm{Tris}-\mathrm{HCl}$ solution compared with those of the metal and composite scaffolds (Fig. 2d). In contrast, the Fe scaffolds demonstrated only a slight weight loss and a slow loss rate. Interestingly, the 30CS scaffolds showed significantly more weight loss than the Fe scaffolds at every monitoring point. Figure 2e, $f$ shows the release of $\mathrm{Ca}$ and $\mathrm{Si}$ elements as a function of the soaking time. There was a rapid increase in the concentration of the two kinds of ions for the $\mathrm{CaSiO}_{3}$ and 30CS scaffolds during the initial 7 days, which was followed by a reduction or a plateau. In the terms of the $\mathrm{Fe}$ ions, the concentration of released Fe was higher for the 30CS scaffolds than for the pure Fe scaffolds (Fig. 2g). On day 1 , the $\mathrm{Fe}$ ion concentration for the 30CS scaffolds reached 3.82 p.p.m., which is higher than that for the Fe scaffolds (1.14 p.p.m.) (Fig. 2g). On day 7, the Fe ion concentrations for the 30CS and Fe scaffolds sintered at $1150^{\circ} \mathrm{C}$ were higher than those for the scaffolds sintered at $1350{ }^{\circ} \mathrm{C}$ (Fig. S4). The sustained release of $\mathrm{Fe}$ ions is beneficial for the continuous production of ROS and for achieving a tumor therapeutic effect. The improvement in the Fe ion release and weight loss of the 30CS scaffolds is attributed to the low value of the activation energy of 


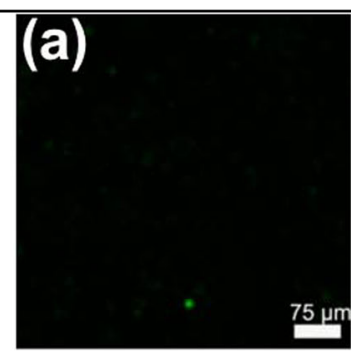

(d)

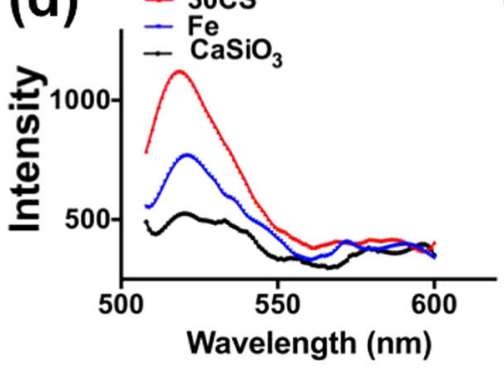

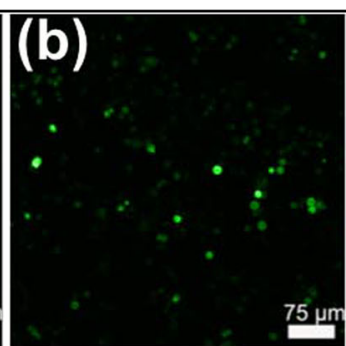

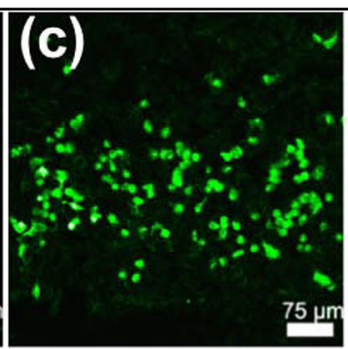

(e)

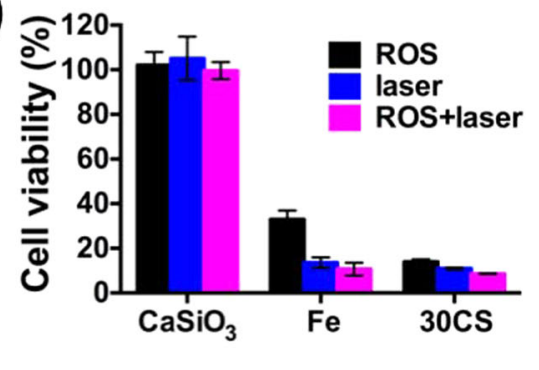

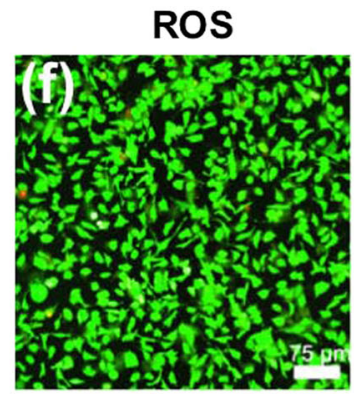
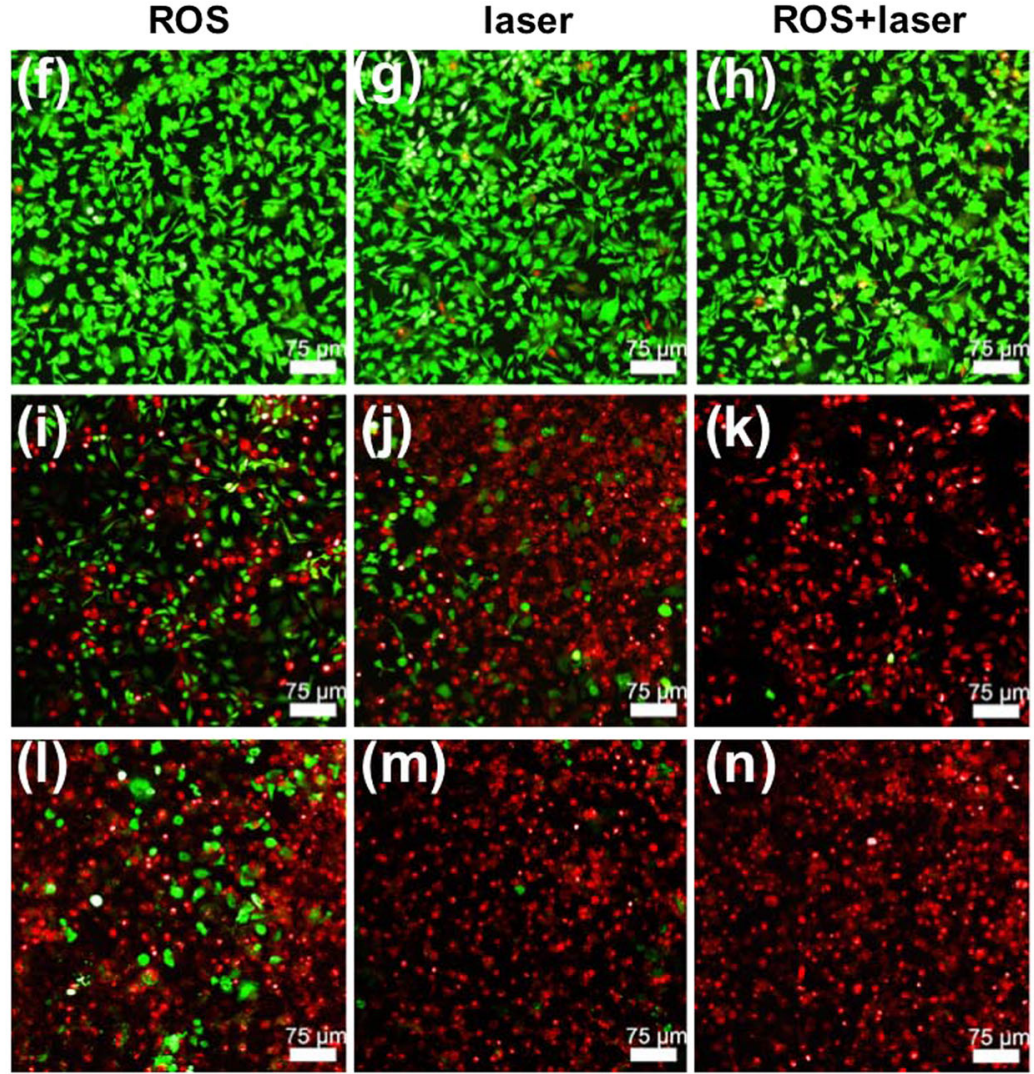

Fig. 3 Green fluorescence images of DCFA-DA-labeled Sao2 tumor cells after incubation with the $\mathrm{CaSiO}_{3}(\mathbf{a})$, Fe (b) and $30 \mathrm{CS}$ (c) scaffolds for $4 \mathrm{~h}$ Fluorescence intensity of the DCFH-DA-labeled Sao2 tumor cells after incubation with the $\mathrm{CaSiO}_{3}, \mathrm{Fe}$, and $30 \mathrm{CS}$ scaffolds for $4 \mathrm{~h}$. $\mathbf{d}$ Fluorescent intensity from DCFH-DA labeled Sao2 tumor cells after incubation with $\mathrm{CaSiO}_{3}$, Fe and 30CS scaffolds for $4 \mathrm{~h}$. e Relative viability of the Sao2 tumor cells after the different treatments. Confocal images of the Saos2 tumor cells treated with the $\mathrm{CaSiO}_{3}(\mathbf{f}-\mathbf{h}), \mathrm{Fe}(\mathbf{i}-\mathbf{k})$ and $30 \mathrm{CS}$ (I-n) scaffolds and then stained with calcein AM (green, live cells) and ethidium homodimer-1 (red, dead cells). The 30CS scaffolds effectively killed the Sao2 tumor cells under the synergistic effects of photothermal ablation and the production of ROS 
$\mathrm{CaSiO}_{3}{ }^{11}$. The possible mechanism may be described as follows: On the one hand, compared with pure Fe scaffolds, the relatively higher solubility of the $\mathrm{CaSiO}_{3}$ phase in the 30CS scaffolds not only induced a higher weight loss but also led to the formation of micropores and thus increased the contact area between the Fe phase and the Tris- $\mathrm{HCl}$ solution. On the other hand, the $\mathrm{Fe}-\mathrm{CaSiO}_{3}$ interface at the $\mathrm{Fe}$ grain boundaries could facilitate fluid diffusion into the bulk since the $\mathrm{CaSiO}_{3}$ bioceramics are hydrophilic and then accelerate Fe dissolution in the Tris$\mathrm{HCl}$ solution to produce a higher released Fe concentration $^{7,24,25}$.

\section{Excellent photothermal effect of the 30CS scaffolds}

The prepared $\mathrm{Fe}-\mathrm{CaSiO}_{3}$ composite scaffolds possessed excellent photothermal properties. Subsequently, the photothermal performance of the scaffolds was investigated systematically under irradiation by an $808 \mathrm{~nm}$ NIR laser. As shown in Fig. 2h,i, the temperature of the $\mathrm{CaSiO}_{3}$ scaffold remained at room temperature after laser irradiation, while the temperature of the Fe scaffold increased dramatically from 0 to $300 \mathrm{~s}$. Such effective NIR laser absorption and scattering by the Fe scaffold are attributed to the localized surface plasmon resonance (LSPR) properties $^{16}$. Interestingly, the 40CS, 30CS and 20CS composite scaffolds exhibited better photothermal properties than the pure Fe scaffold in both dry (air) and wet (PBS) environments. In addition, the 30CS composite scaffolds exhibited a power density-dependent photothermal effect (Fig. 2j, k). It was found that the temperature of the 30CS scaffolds in PBS rapidly increased to $50^{\circ} \mathrm{C}$ at a power density of $0.6 \mathrm{~W} / \mathrm{cm}^{2}$ within $10 \mathrm{~min}$, exhibiting an excellent photothermal effect. A more straightforward temperature comparison can be obtained from infrared thermal images (Fig. 21).

We also investigated the effect of the power density on the viability of rBMSCs. Laser power densities of $0.16,0.27$, and $0.44 \mathrm{~W} / \mathrm{cm}^{2}$ were chosen, and the temperature induced by the $30 \mathrm{CS}$ scaffolds was $44,48,52^{\circ} \mathrm{C}$, respectively. As shown in Fig. S6, compared with the $\mathrm{CaSiO}_{3}$ group, the cell viability in the 30CS scaffolds decreased following laser irradiation $\left(0.16 \mathrm{~W} / \mathrm{cm}^{2}\right)$ for $15 \mathrm{~min}$. However, the number of rBMSCs significantly increased on day 3 in the $30 \mathrm{CS}+$ laser group after laser irradiation at $0.16 \mathrm{~W} / \mathrm{cm}^{2}$, suggesting that the short-term thermal therapy had no negative effects on long-term cell proliferation. (Fig. S6)

\section{Reactive oxygen species produced by the 30CS scaffolds in vitro}

The prepared $\mathrm{Fe}-\mathrm{CaSiO}_{3}$ composite scaffolds can produce ROS through the interaction of the released Fe ions with $\mathrm{H}_{2} \mathrm{O}_{2}$ inside the tumor. Considering the sustained release of Fe ions from the 30CS scaffolds in a Tris- $\mathrm{HCl}$ solution, the formation of ROS in the Fe-catalyzed decomposition of $\mathrm{H}_{2} \mathrm{O}_{2}$ was characterized in vitro. First, Sao2 tumor cells were incubated with the $\mathrm{CaSiO}_{3}, \mathrm{Fe}$ and $30 \mathrm{CS}$ scaffolds for $4 \mathrm{~h}$. The scaffolds were removed, and $2^{\prime}$ 7'-dichlorodi-hydrofluorescein diacetate (DCFH-DA) fluorescent agent was added for $20 \mathrm{~min}$. As shown in Fig. 3a-c, the Sao2 cells incubated with the 30CS scaffolds exhibited enhanced green fluorescence compared with those incubated with the Fe scaffolds because the Fe ion concentration released from the 30CS composite scaffolds was higher than that from the pure Fe scaffolds. Meanwhile, almost no fluorescence was observed in the Sao2 tumor cells treated with $\mathrm{CaSiO}_{3}$ scaffolds, suggesting that no ROS were produced in the $\mathrm{CaSiO}_{3}$ scaffold group. The fluorescence intensity was also measured with a fluorescence spectrometer. The results showed that the intensity of fluorescence in the 30CS group was higher than that in the pure $\mathrm{Fe}$ and $\mathrm{CaSiO}_{3}$ groups (Fig. 3d). As has been reported, under the function of ROS, DCFH is converted to DCF, which emits fluorescence at $525 \mathrm{~nm}$ under an excitation wavelength of $480 \mathrm{~nm}^{20}$. The production of ROS is attributed to the Fe ions released from the 30CS scaffolds. The released Fe ions are proposed to catalyze the degradation of $\mathrm{H}_{2} \mathrm{O}_{2}$ in tumor cells by the Fenton reaction, as follows: $\mathrm{Fe}^{2+}+\mathrm{H}_{2} \mathrm{O}_{2} \rightarrow \mathrm{Fe}^{3+}+\mathrm{HO}+\mathrm{HO}^{-}$or $\mathrm{Fe}^{3+}+\mathrm{H}_{2} \mathrm{O}_{2} \rightarrow \mathrm{Fe}^{2+}+\mathrm{HOO}+\mathrm{H}^{+17,26}$.

\section{Enhanced antitumor effects of the synergistic therapies in vitro}

The most distinctive characteristic of the prepared Fe$\mathrm{CaSiO}_{3}$ composite scaffolds was that they can synergistically treat bone tumors in vitro and in vivo via the photothermal effect and ROS. Sao2 tumor cells were first cultured on slice glass and then divided into nine groups: those incubated with $\mathrm{CaSiO}_{3}$, Fe or 30CS scaffolds for $4 \mathrm{~h}$ without laser irradiation to evaluate the effect of ROS on the tumor cells; those treated with $\mathrm{CaSiO}_{3}$, Fe or 30CS scaffolds with laser irradiation for $15 \mathrm{~min}$ at a power density of $0.6 \mathrm{~W} / \mathrm{cm}^{2}$ followed by immediate removal of the scaffolds to test the effect of photothermal ablation on the tumor cells; and those incubated with $\mathrm{CaSiO}_{3}, \mathrm{Fe}$ or 30CS scaffolds for $4 \mathrm{~h}$ followed by laser irradiation for $15 \mathrm{~min}$ to investigate the combinatorial effects of the ROS and photothermal therapy. According to live/dead and CCK-8 assays, it was found that after irradiation for $15 \mathrm{~min}$ and incubation with the 30CS scaffolds for $4 \mathrm{~h}$, the mortality rate of the tumor cells reached $91.4 \%$, the highest among the nine groups, indicating the enhanced efficacy of the synergistic photothermal and ROS therapies (Fig. 3e-n). The anticancer performance of the Fe scaffolds was not as good as that of the 30CS scaffolds because of the lower released Fe ion concentration and the slightly lower photothermal performance of the Fe scaffolds relative to those of the 30CS scaffolds. In 
contrast, nearly all the tumor cells treated with the $\mathrm{CaSiO}_{3}$ scaffolds were alive (Fig. $3 \mathrm{f}-\mathrm{h}$ ). The antitumor mechanisms of the 30CS scaffolds are as follows. On the one hand, the controllable high temperature (above $50^{\circ} \mathrm{C}$ ) induced by laser irradiation of the 30CS scaffolds led to cell membrane collapse, coagulative necrosis, protein denaturation, mitochondrial dysfunction and a halt in enzyme activity ${ }^{27,28}$. On the other hand, the excessive production of ROS in the tumor cells resulted in rapid lipid oxidation and protein and DNA damage ${ }^{17,29,30}$.

The biocompatibility with rBMSCs was also tested via CCK- 8 assay after treatment with the $\mathrm{CaSiO}_{3}, \mathrm{Fe}$, and 30CS composite scaffolds. As shown in Fig. S5, there was no obvious change in the cell viability after treatment with the $\mathrm{CaSiO}_{3}, \mathrm{Fe}$, or 30CS composite scaffolds for $4 \mathrm{~h}$. Comparison with the tumor cell viability under the same treatment suggests that rBMSCs can survive better than cancer cells under this treatment.

\section{Enhanced antitumor effect of the synergistic therapies in vivo}

Based on the effective synergistic photothermal/ROS therapy in vitro, the 30CS composite scaffolds may have great potential for application as novel bifunctional scaffolds in the treatment of tumors in vivo. First, $\mathrm{CaSiO}_{3}, \mathrm{Fe}$ and 30CS scaffolds (length: $6 \mathrm{~mm}$, width: $1.5 \mathrm{~mm}$, height: $1.5 \mathrm{~mm}$ ) were implanted in the center of tumors in mice, Subsequently, the mice were divided into six groups: those implanted with $\mathrm{CaSiO}_{3}$, Fe or 30CS scaffolds without laser irradiation and those implanted with $\mathrm{CaSiO}_{3}$, Fe or 30CS scaffolds with laser irradiation for $15 \mathrm{~min}$. It was found that the temperatures of the tumors implanted with the 30CS scaffolds increased rapidly to above $50^{\circ} \mathrm{C}$ under laser irradiation at a power density of $\sim 0.8 \mathrm{~W} / \mathrm{cm}^{2}$ for $10 \mathrm{~min}$, which was slightly higher than the temperature induced by the Fe scaffolds (Fig. 4a). The high temperature spanned all of the tumor tissue. In contrast, the tumors implanted with $\mathrm{CaSiO}_{3}$ scaffolds exhibited a temperature increase of only $5^{\circ} \mathrm{C}$ under NIR irradiation for $10 \mathrm{~min}$. The volume of the tumor tissue in the Fe and 30CS scaffold groups without irradiation was obviously smaller than that in the $\mathrm{CaSiO}_{3}$ and $\mathrm{CaSiO}_{3}+$ laser groups, indicating that the ROS produced by the cumulative release of Fe ions in the tumors possessed in vivo antitumor efficiency to some extent (Fig. 4b, d). As shown in Fig. 4b, d, among the six groups, the group implanted with 30CS scaffolds with irradiation exhibited the most effective tumor cell killing and significantly inhibited tumor growth, suggesting the efficacy of the synergistic photothermal and ROS therapies in vivo. The mice were sacrificed on the 15th day post treatment. The tumor tissue was collected and stained with H\&E. According to the H\&E images (Fig. 5a-f), in the 30CS + laser and Fe + laser groups, the tumor cells suffered serious fibrosis, and almost all the cell nuclei dissolved, indicating remarkable destruction by the photothermal and ROS treatments. For the tumor cells treated with 30CS and Fe scaffolds without irradiation, only the cells near the scaffolds were destroyed, indicating the limited antitumor performance of these scaffolds. However, the tumor cells treated with $\mathrm{CaSiO}_{3}$ or $\mathrm{CaSiO}_{3}$ + laser showed no noticeable damage. The results above suggest that the 30CS scaffolds, as a localized photothermal agent, can be utilized to selectively kill tumor cells while causing minimal damage to normal cells. In addition, the release of Fe ions results in the production of ROS, which kill the possible residual tumor cells around the scaffolds. Moreover, the synergistic photothermal and ROS therapies can achieve a satisfactory therapeutic effect under laser irradiation at a low power density to avoid skin injury induced by too high of a temperature.

In our work, there are three factors of selectivity in the photothermal therapy and ROS process. One is that the production of ROS does more harm to cancer cells than to healthy cells because of the higher amounts of $\mathrm{H}_{2} \mathrm{O}_{2}$ in tumor cells. A previous study has indicated that the increase in $\mathrm{H}_{2} \mathrm{O}_{2}$ in tumor cells is linked to several obvious alterations by the cancer, including DNA alterations, cell proliferation, apoptosis resistance, metastasis, cell proliferation, angiogenesis and hypoxia-inducible factor 1 activation $^{31}$. The second factor is that certain tumor cells, such as breast cancer cells, display more transferrin receptors than normal, healthy cells, leading to higher intracellular concentrations of iron ions in the tumor cells ${ }^{32,33}$. The final factor is the temperature of the tissue that was detected during photothermal therapy in real-time via infrared thermal images. As shown in Fig. 4, a temperature gradient exists across the 30CS composited scaffolds, which functioned as photothermal agents. Therefore, an appropriate power density was chosen to ensure that the temperature of the tumor tissue was above $48{ }^{\circ} \mathrm{C}$ and that the temperature of the healthy tissue remained below $45^{\circ} \mathrm{C}$ to protect the healthy bone cells. If almost all the tumor cells were killed and only a few healthy bone cells were killed under laser irradiation, the 30CS scaffolds would further promote the proliferation of rBMSCs and the regeneration of bone tissue in the long term.

\section{In vitro osteogenesis of the 30CS scaffolds}

Finally, the prepared $\mathrm{Fe}-\mathrm{CaSiO}_{3}$ composite scaffolds possessed exhibited good compatibility and bone-forming ability in vitro and in vivo. To evaluate the biocompatibility of the 30CS scaffolds, the effects of the ionic extracts of the $\mathrm{CaSiO}_{3}, \mathrm{Fe}$ and 30CS powders and scaffolds on the proliferation of rBMSCs were investigated (Fig. 6a-c, Fig. S7). A CCK-8 assay revealed that the ionic extracts of the $\mathrm{CaSiO}_{3}, \mathrm{Fe}$ and $30 \mathrm{CS}$ powders with 

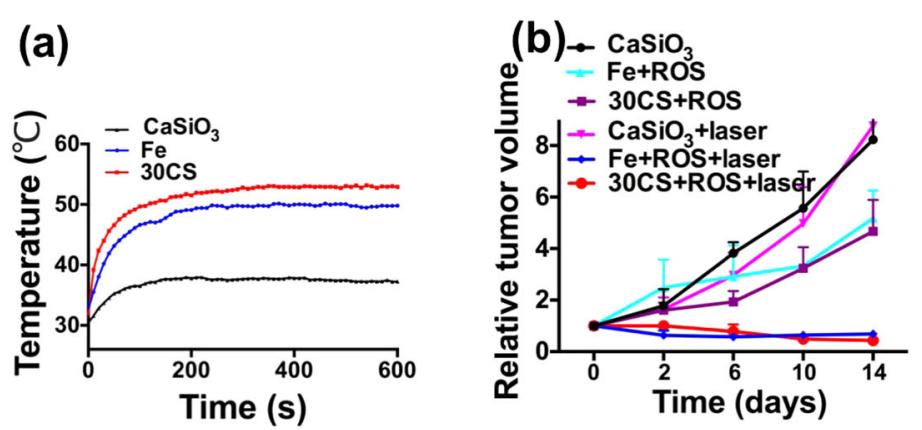

(c)

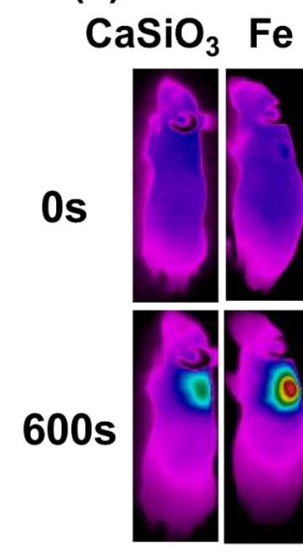

(d)

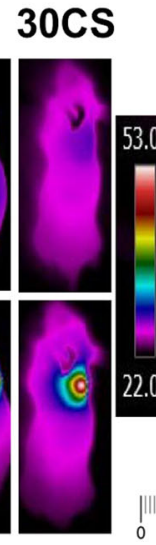

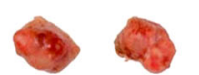

(2) $\mathrm{CaSiO}_{3}$

a 1 Fe+ROS

- 30CS+ROS

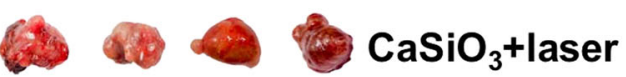

- $-\mathrm{Fe}+\mathrm{ROS}+\mathrm{laser}$

- $\quad 30 \mathrm{CS}+\mathrm{ROS}+\mathrm{laser}$

${ }_{0}^{||||||||||||||||||||||||||||||||||||||||||||||||||||||||||||||||||||||||||||||||||||||||||||}$

Fig. 4 a Heating curve of tumor-bearing mice implanted with $\mathrm{CaSiO}_{3}$, Fe, and $30 \mathrm{CS}$ scaffolds under irradiation by an $808 \mathrm{~nm}$ laser. $\mathbf{b}$ Change in the tumor volume over time in the six groups (b). c Infrared radiation (IR) thermal images of tumor-bearing mice under irradiation by an $808 \mathrm{~nm}$ laser for $600 \mathrm{~s}$. d Photographs of the tumors from the six groups on day 15

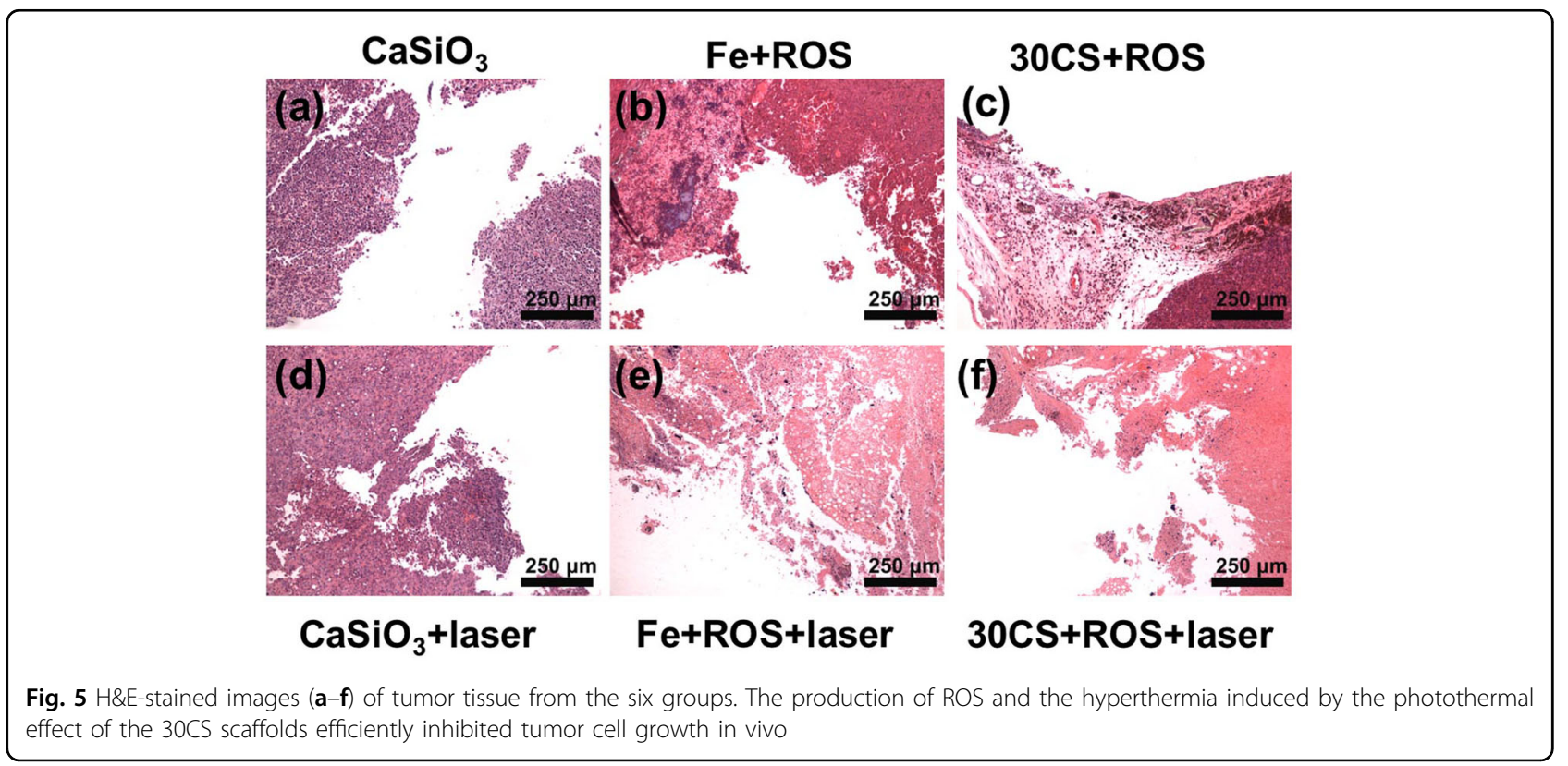




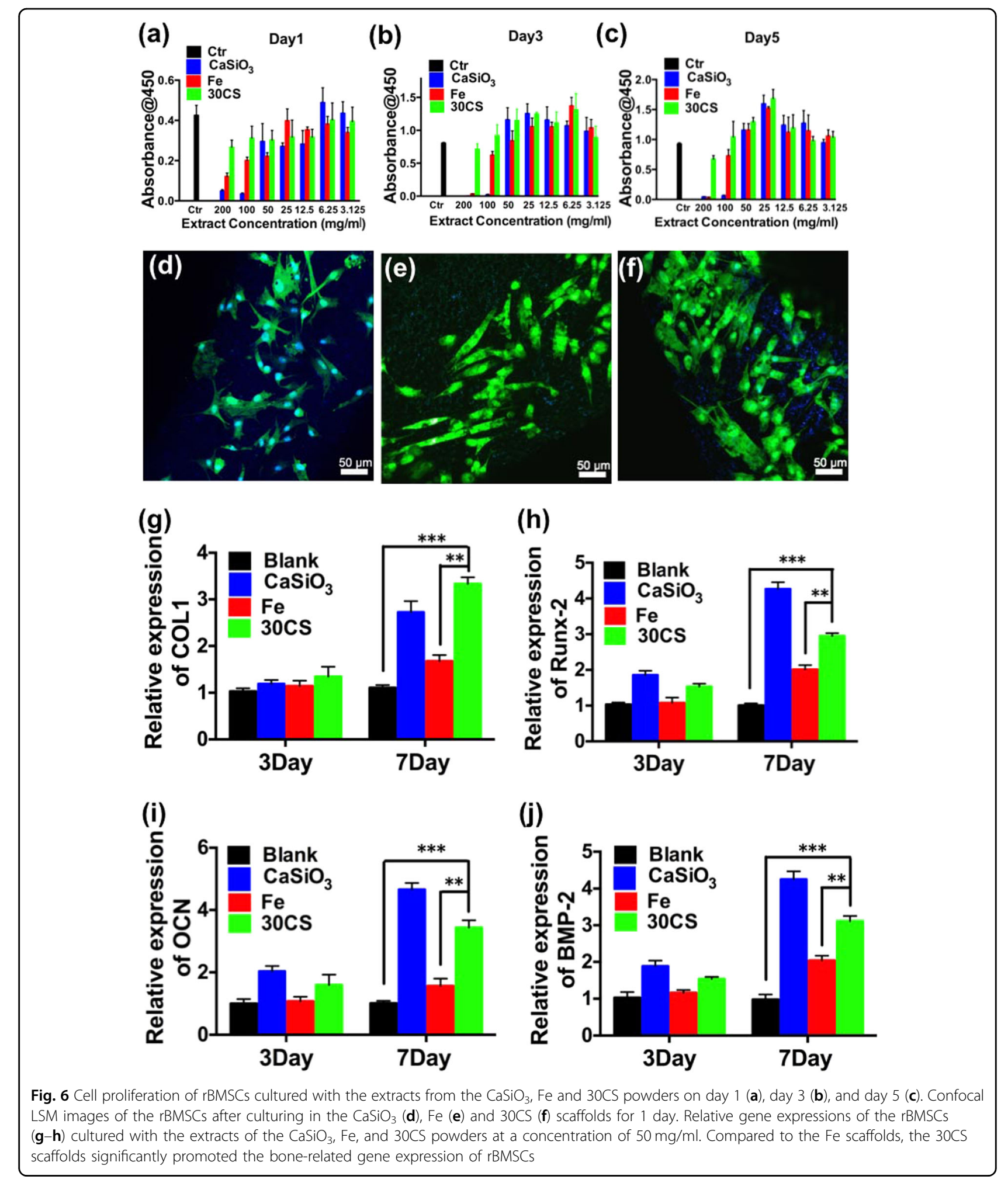

concentrations from $50 \mathrm{mg} / \mathrm{mL}$ to $3.125 \mathrm{mg} / \mathrm{mL}$ had no adverse effect on the viability of rBMSCs and supported the proliferation of the rBMSCs (Fig. $6 \mathrm{a}-\mathrm{c}$ ). In addition, the rBMSCs even proliferated well with the highly concentrated ionic extracts from the 30CS powder (200 and $100 \mathrm{mg} / \mathrm{mL}$ ) compared to the control group over 5 days, suggesting the good biocompatibility of this material. The morphology and attachment of the rBMSCs 


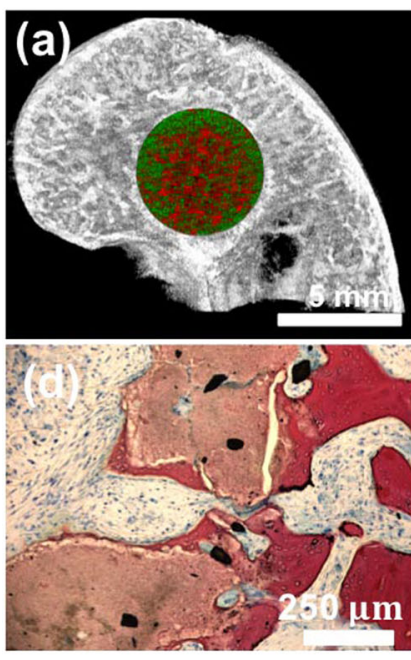

(g)

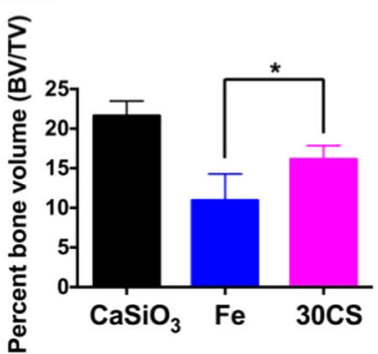

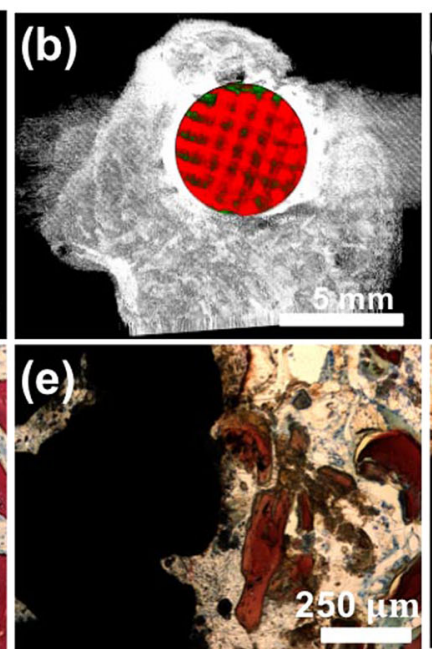

(h)

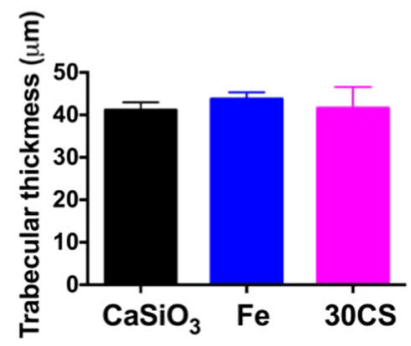

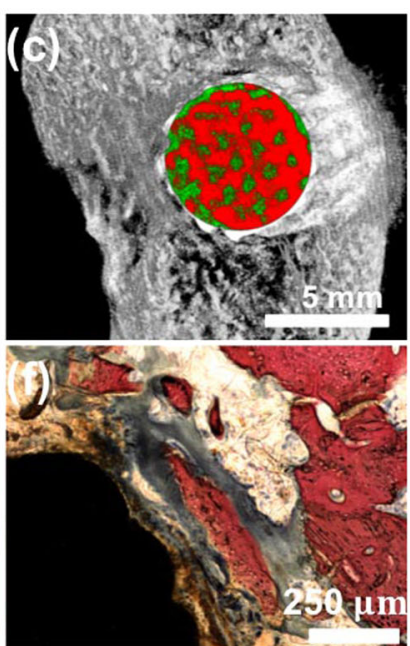

(i)

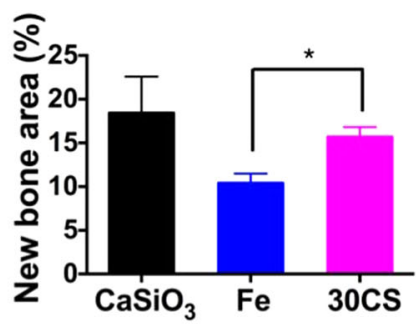

Fig. 7 Micro-CT images $(\mathbf{a}-\mathbf{c})$ and statistical analysis $(\mathbf{g}, \mathbf{h})$ of the defects in the $\mathrm{CaSiO}_{3}, \mathrm{Fe}$, and $30 \mathrm{CS}$ groups 8 weeks post surgery. Histological analysis $(\mathbf{d}-\mathbf{f})$ and histomorphometric measurements (i) of in vivo osteogenesis for the $\mathrm{CaSiO}_{3}$, Fe, and $30 \mathrm{CS}$ scaffolds 8 weeks post surgery. The $30 \mathrm{CS}$ scaffolds better promoted in vivo bone formation than the pure Fe scaffolds. $\left({ }^{*} p<0.05\right)$

in the $\mathrm{CaSiO}_{3}, \mathrm{Fe}$ and 30CS scaffolds were observed by confocal LSM and SEM. It was found that the rBMSCs attached and spread well on the pore walls of the $\mathrm{CaSiO}_{3}$, Fe and 30CS scaffolds, indicating the favorable biocompatibility of the scaffolds (Fig. 6d-f and Fig. S8). To evaluate the effects of the ionic extracts on stimulating the differentiation of rBMSCs, the expression of typical bonerelated genes was analyzed. The expression of COL I, OCN, Runx2, BMP-2, which are typical markers of osteogenic differentiation, in the $\mathrm{CaSiO}_{3}$ and 30CS groups was significantly up-regulated on day 7 compared to that of the control group and Fe group, which was attributed to the presence of $\mathrm{CaSiO}_{3}$ (Fig. $6 \mathrm{~g}-\mathrm{j}$ ). It has been reported that $\mathrm{CaSiO}_{3}$ can enhance the cross-talk between endothelia cells and bone marrow stromal cells through VEGF and BMP-2 and further stimulate vascularization and osteogenic differentiation $^{12}$.

\section{In vivo osteogenesis of the 30CS scaffolds}

The in vivo osteogenic capability of the $\mathrm{CaSiO}_{3}, \mathrm{Fe}$ and 30CS scaffolds was further explored to evaluate their potential for clinical application in the future. Twelve
New Zealand white rabbits $(2-2.5 \mathrm{~kg})$ were used as critical-sized femoral defect models. After defects were created, $\mathrm{CaSiO}_{3}, \mathrm{Fe}$ and $30 \mathrm{CS}$ scaffolds (height: $8 \mathrm{~mm}$, diameter: $5 \mathrm{~mm}$ ) were implanted followed by irradiation at a power density of $0.8 \mathrm{~W} / \mathrm{cm}^{2}$ for $10 \mathrm{~min}$ to verify that the short-term photothermal therapy had no adverse effects on long-term bone regeneration. After 8 weeks, the rabbits were sacrificed, and the species were collected. From histological and micro-CT analyses, it was clear that the percentage of newly formed bone in the 30CS composite scaffolds was remarkably higher than that in the Fe scaffolds (Fig. 7a-i). The good bone compatibility and conductivity of the 30CS composite ceramics was attributed to the surface reaction of $\mathrm{CaSiO}_{3}$ with the surrounding bodily fluids and the formation of bone-like apatite on the surface of the scaffolds ${ }^{34}$. On the one hand, the $\mathrm{CaSiO}_{3}$ ceramic phase exhibited enhanced degradation relative to that of pure Fe, thus enforcing the degradation of the entire composite scaffold and resulting in faster penetration of the bone cells in the bone substitute material. On the other hand, the released Si was closely associated with metabolism, collagen synthesis, 
and bone mineralization, stimulated osteoblast proliferation and differentiation, and further influenced skeletal and vascular development ${ }^{35,36}$. Additionally, Ca ions were proven to influence the osteogenic differentiation and mineralization of BMSCs and osteoblasts ${ }^{37,38}$.

In summary, an optimal $\mathrm{Fe}-\mathrm{CaSiO}_{3}$ composite scaffold (30CS) with distinct mechanical, degradation, photothermal and biological properties was successfully prepared by 3D printing. Impressively, as novel bifunctional biomaterials, the 30CS composite scaffolds possess a high compressive strength for load-bearing application in the cortical bone defects induced by bone cancer. Benefiting from the excellent photothermal effect and the sustained release of Fe ions from the 30CS scaffolds, the synergistic photothermal and ROS therapies achieved a more satisfactory therapeutic effect than the monomodal therapies. The presence of $\mathrm{CaSiO}_{3}$ in the composite scaffolds improved the degradation performance, stimulated the proliferation and differentiation of rBMSCs, and further promoted bone formation in vivo. Therefore, the prepared $\mathrm{Fe}-\mathrm{CaSiO}_{3}$ composite scaffolds can function as versatile and efficient biomaterials for the future regeneration of cortical bone and the treatment of cortical bone cancer, thus representing a universal platform for material science, tissue engineering and tumor therapy.

\section{Statistical analysis}

All the data were expressed as the mean \pm standard deviation (SD) and analyzed using one-way ANOVA with a post hoc test. A $p$-value $<0.05$ was considered statistically significant, and the data were indicated with $\left(^{*}\right)$ for probability less than $0.05(p<0.05)$, $\left.{ }^{(* *)}\right)$ for $p<0.01$, and $(* * *)$ for $p<0.001$.

\section{Data availability}

The data that support the findings of this study are available within the paper and in the Supplementary Information.

\section{Acknowledgements}

This work was supported by the National Key Research and Development Program of China (2016YFB0700803), the Natural Science Foundation of China (81771989, 81401529, 81572156), the Key Research Program of Frontier Sciences CAS (QYZDB-SSW-SYS027), the Science and Technology Commission of Shanghai Municipality (17441903700, 16DZ2260603, 17540712300), the Key Research Program of Science and Technology Support Program of Jiangsu Province (BE2016763), and the Shanghai Municipal Education CommissionGaofeng Clinical Medicine Grant Support (20152224).

\footnotetext{
Author details

${ }^{1}$ State Key Laboratory of High Performance Ceramics and Superfine Microstructure, Shanghai Institute of Ceramics, Chinese Academy of Sciences, 200050 Shanghai, People's Republic of China. ${ }^{2}$ University of Chinese Academy of Sciences, 100043 Beijing, People's Republic of China. ${ }^{3}$ Shanghai Key Laboratory of Orthopaedic Implant, Department of Orthopaedic Surgery, Shanghai Ninth People's Hospital, Shanghai Jiao Tong University School of Medicine, 200011 Shanghai, People's Republic of China
}

Conflict of interest

The authors declare that they have no conflict of interest.

\section{Publisher's note}

Springer Nature remains neutral with regard to jurisdictional claims in published maps and institutional affiliations.

Supplementary information is available for this paper at https://doi.org/ 10.1038/s41427-018-0015-8.

Received: 19 September 2017 Revised: 7 December 2017 Accepted: 8 January 2018.

Published online: 3 April 2018

\section{References}

1. Verron, E. et al. Therapeutic strategies for treating osteolytic bone metastases. Drug Discov. Today 19, 1419-1426 (2014).

2. He, Q. \& Shi, J. MSN anti-cancer nanomedicines: chemotherapy enhancement, overcoming of drug resistance, and metastasis inhibition. Adv. Mater. 26, 391-411 (2013)

3. Luetke, A., Meyers, P. A., Lewis, I. \& Juergens, H. Osteosarcoma treatmentWhere do we stand? A state of the art review. Cancer Treat. Rev. 40, 523-532 (2014).

4. Kohn, D. H., Sarmadi, M., Helman, J. I. \& Krebsbach, P. H. Effects of pH on human bone marrow stromal cells. J. Biomed. Mater. Res. 103, 292-299 (2002).

5. Tampieri, A. et al. Intrinsic magnetism and hyperthermia in bioactive Fe-doped hydroxyapatite. Acta Biomater. 8, 843-851 (2012).

6. Vlad, M. D. et al. Osteogenic biphasic calcium sulphate dihydrate/iron-modified a-tricalcium phosphate bone cement for spinal applications: In vivo study. Acta Biomater. 6, 607-616 (2010).

7. Ulum, M. F. et al. Evidences of in vivobioactivity of Fe-bioceramic composites for temporary bone implants. J. Biomed. Mater. Res. 103, 1354-1365 (2014).

8. Peuster, M. Long-term biocompatibility of a corrodible peripheral iron stent in the porcine descending aorta. Biomaterials 27, 4955-4962 (2006).

9. Kraus, T. et al. Biodegradable Fe-based alloys for use in osteosynthesis: outcome of an in vivo study after 52 weeks. Acta Biomater. 10, 3346-3353 (2014).

10. Zhang, X.-Y., Fang, G. \& Zhou, J. Additively manufactured scaffolds for bone tissue engineering and the prediction of their mechanical behavior: a review. Materials 10, E50 (2017). 50-28.

11. Ni, S. \& Chang, J. In vitro degradation, bioactivity, and cytocompatibility of calcium silicate, dimagnesium dilicate, and tricalcium phosphate bioceramics. J. Biomater. Appl. 24, 139-158 (2009).

12. Li, H., Xue, K., Kong, N., Liu, K. \& Chang, J. Silicate bioceramics enhanced vascularization and osteogenesis through stimulating interactions between endothelia cells and bone marrow stromal cells. Biomaterials 35, 3803-3818 (2014). (9999).

13. Cheng, L., Wang, C., Feng, L., Yang, K. \& Liu, Z. Functional nanomaterials for phototherapies of cancer. Chem. Rev. 114, 10869-10939 (2014).

14. Liu, Y. et al. Dopamine-melanin colloidal nanospheres: an efficient nearinfrared photothermal therapeutic agent for in vivo cancer therapy. Adv. Mater. 25, 1353-1359 (2013)

15. Dong, W. et al. Facile synthesis of monodisperse superparamagnetic $\mathrm{Fe}_{3} \mathrm{O}_{4}$ core@hybrid@Au shell nanocomposite for bimodal imaging and photothermal therapy. Adv. Mater. 23, 5392-5397 (2011).

16. Chong, X., Abboud, J. \& Zhang, Z. Plasmonics resonance enhanced active photothermal effects of aluminum and iron nanoparticles. J. Nanosci. Nanotechnol. 15, 2234-2240 (2015).

17. $\mathrm{Xu}, \mathrm{C}$. et al. FePt nanoparticles as an Fe reservoir for controlled Fe release and tumor inhibition. J. Am. Chem. Soc. 131, 15346-15351 (2009).

18. Song, X.-R. et al. $\mathrm{Co}_{9} \mathrm{Se}_{8}$ nanoplates as a new theranostic platform for photoacoustic/magnetic resonance dual-modal-imaging-guided chemophotothermal combination therapy. Adv. Mater. 27, 3285-3291 (2015).

19. Zhang, J. et al. Self-monitoring and self-delivery of photosensitizer-doped nanoparticles for highly effective combination cancer therapy in vitro and in vivo. ACS Nano 9, 9741-9756 (2015). 
20. Reindl, A. et al. Degradation behavior of novel Fe/ $\beta$-TCP composites produced by powder injection molding for cortical bone replacement. J. Mater. Sci. 49 8234-8243 (2014).

21. Ulum, M. F. et al. In vitro and in vivo degradation evaluation of novel ironbioceramic composites for bone implant applications. Mater. Sci. Eng. C 36, 336-344 (2014)

22. Nouri, A. \& Wen, C. Surfactants in mechanical alloying/milling: a catch-22 situation. Crit. Rev. Solid State 39, 81-108 (2013).

23. Kato, K. et al. Novel multilayer Ti foam with cortical bone strength and cytocompatibility. Acta Biomater. 9, 5802-5809 (2013).

24. Patel, A. \& Knowles, J. C. Investigation of silica-iron-phosphate glasses for tissue engineering. J. Mater. Sci. Mater. Med. 17, 937-944 (2006).

25. Mohammadi, M. S. et al. Effect of Si and Fe doping on calcium phosphate glass fibre reinforced polycaprolactone bone analogous composites. Acta Biomater. 8, 1616-1626 (2012)

26. Sahu, N. K., Gupta, J. \& Bahadur, D. PEGylated FePt-Fe 30 4composite nanoassemblies (CNAs): in vitro hyperthermia, drug delivery and generation of reactive oxygen species (ROS). Dalton Trans. 44, 9103-9113 (2015).

27. $\mathrm{Ma}, \mathrm{H}$. et al. A bifunctional biomaterial with photothermal effect for tumor therapy and bone regeneration. Adv. Funct. Mater. 26, 1197-1208 (2016)

28. Chu, K. F. \& Dupuy, D. E. Thermal ablation of tumours: biological mechanisms and advances in therapy. Nat. Rev. 14, 199-208 (2014).

29. Papanikolaou, G. \& Pantopoulos, K. Iron metabolism and toxicity. Toxicol. Appl. Pharm. 202, 199-211 (2005).
30. Zhang, Y. et al. Dietary iron oxide nanoparticles delay aging and ameliorate neurodegeneration in Drosophila. Adv. Mater. 28, 1387-1393 (2015).

31. López-Lázaro, M. Dual role of hydrogen peroxide in cancer: possible relevance to cancer chemoprevention and therapy. Cancer Lett. 252, 1-8 (2007).

32. Reizenstein, P. Iron, Free radicals and cancer. Med. Oncol. Tumor Pharrnacother 8, 229-233 (1991)

33. Lamy, P.-J., Durigova, A. \& Jacot, W. Iron homeostasis and anemia markers in early breast cancer. Clin. Chim. Acta 434, 34-40 (2014).

34. Xu, S. et al. Reconstruction of calvarial defect of rabbits using porous calcium silicate bioactive ceramics. Biomaterials 29, 2588-2596 (2008).

35. Wang, C., Lin, K., Chang, J. \& Sun, J. Osteogenesis and angiogenesis induced by porous $\beta-\mathrm{CaSiO}_{3} / \mathrm{PDLGA}$ composite scaffold via activation of AMPK/ERK1/2 and PI3K/Akt pathways. Biomaterials 34, 64-77 (2013). 9999.

36. Valerio, P., Pereira, M. M., Goes, A. M. \& Leite, M. F. The effect of ionic products from bioactive glass dissolution on osteoblast proliferation and collagen production. Biomaterials 25, 2941-2948 (2004).

37. Maeno, S. et al. The effect of calcium ion concentration on osteoblast viability, proliferation and differentiation in monolayer and 3D culture. Biomaterials $\mathbf{2 6}$ 4847-4855 (2005).

38. $\mathrm{Gu}, \mathrm{H}$. et al. The stimulation of osteogenic differentiation of human adiposederived stem cells by ionic products from akermanite dissolution via activation of the ERK pathway. Biomaterials 32, 7023-7033 (2011). 